296

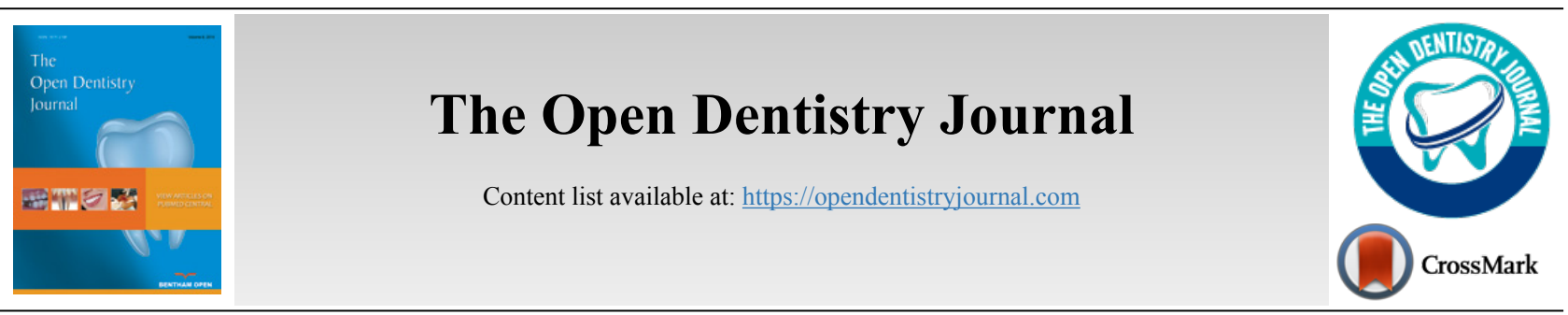

REVIEW ARTICLE

\title{
Public Health Dentist: An Untapped Potential during COVID-19 Pandemic
}

\author{
Gargi C. Nimbulkar ${ }^{1}$, Kumar G. Chhabra, ${ }^{1, *}$, Shravani Deolia ${ }^{2}$ and B Unnikrishnan ${ }^{3}$ \\ ${ }^{I}$ Department of Public Health Dentistry, Sharad Pawar Dental College, Datta Meghe Institute of Medical Sciences (DU), Sawangi, Wardha, India \\ ${ }^{2}$ Vidya Cancer Hospital, Gwalior, India \\ ${ }^{3}$ Department of Community Medicine, Kasturba Medical College, Mangalore, India
}

\begin{abstract}
:
To date, the $21^{\text {st }}$ century has encountered various outbreaks, causing global disruption and highlighting our vulnerability to epidemics. Coronavirus disease (COVID-19) is a highly infectious respiratory illness. Approximately $15 \%$ of the affected individuals show severe symptoms requiring oxygen, and of these, $5 \%$ require ventilation. This pandemic has affected more than 216 countries or territories (by $20^{\text {th }}$ September 2020 ), infecting more than 30.6 million people; hitherto, 950000 deaths have been reported. This public health emergency has created a disproportionate burden on the health care system worldwide. Therefore, the management and resolution of this critical situations require the mobilisation of excessive human resources for rapid response, and time is essential in the management of this crisis. Together, these factors contribute to the rapid capacity development with the minimal investment of time and resources, which requires the deployment of an existing skilled workforce, such as public health dentists. These dentists have administrative capabilities and can work in coherence with the community and other health professionals. The present review aims to highlight the areas in which the untapped potential of Public Health Dentists can be explored to tackle the COVID-19 pandemic.
\end{abstract}

Keywords: COVID-19, Public health dentist, Pandemic, Manpower, Dentists, Outbreak.

\begin{tabular}{|l|l|l|l|}
\hline Article History & Received: September 18, 2020 & Revised: November 6, 2020 & Accepted: December 26, 2020
\end{tabular}

\section{INTRODUCTION}

Hitherto, the $21^{\text {st }}$ century has experienced critical episodes, rendering the world susceptible to novel microorganisms prompting severe illnessesThis sentence is extremely convoluted with no meaning. Please consider rephrasing.

The H1N1 influenza pandemic in 2009 demonstrated how a new virus could quickly spread worldwide [1]. Severe acute respiratory syndrome (SARS) in 2003 proved that these pathogens affect both wealthy and underdeveloped countries irrespective of the standard of living and healthcare systems. The Ebola outbreak was an alarm for the world to be prepared for various disease outbreaks [1].

In late December 2019, patients with pneumonia of unknown cause were identified in Wuhan, China. The first case was reported on $31^{\text {st }}$ December 2019 to the World Health Organization (WHO) office in China [2]. Further investigation pinpointed a disease caused by the novel coronavirus SARScoronavirus-2 (CoV-2). On $11^{\text {th }}$ February 2020, the WHO named the disease as coronavirus disease of 2019 (COVID-19)

\footnotetext{
* Address correspondence to this author at Department of Public Health Dentistry, Sharad Pawar Dental College, Datta Meghe Institute of Medical Sciences (DU), Sawangi, Wardha, India; Tel: +7976840339;

E-mail: rajsushil.chhabra@gmail.com
}

[3]. Since then, it has spread globally, leading the WHO to declare the outbreak of COVID-19 as a public health emergency of international concern on $30^{\text {th }}$ January 2020 [2].

The mode of transmission is through direct contact with small droplets of nasal or oral origin that spreads from a COVID-19-infected person while coughing or exhaling [4]. These droplets settle on objects or surfaces and can come in contact with people and cause the infection when the person touches their nose, eyes, or mouth [4]. The simplest and the most effective preventive measures include maintaining hand and respiratory hygiene, maintaining at least $1 \mathrm{~m}$ between an individual and the person coughing or sneezing, and social distancing [4]. However, the nature of the illness is usually mild among children and young adults [4].

The estimated incubation period is 1-14 (average, 5) days [4]. The most common symptoms include dry cough, tiredness, and fever. The other symptoms include aches, sore throat, nasal congestion, runny nose, or diarrhoea [4]. These symptoms begin gradually and are usually mild. Data suggest that $80 \%$ of the infected individuals show mild symptoms or are asymptomatic, $15 \%$ suffer from a severe infection, needing oxygen supplementation, and $5 \%$ of the affected belong to the critical infection category, requiring mechanical ventilation [5]. 
Older people and those with comorbidities, such as diabetes mellitus, hypertension, and cardiac conditions, constitute the vulnerable group [4].

\section{GLOBAL AND INDIAN SCENARIO}

As of $15^{\text {th }}$ May 2020, 213 countries, areas, or territories reported 4,258,666 infected individuals and 2,941,904 COVID-19-related deaths [6]. India reported its first COVID-19 case on $30^{\text {th }}$ January 2020 . The infected person had a travel history from Wuhan, China, to India. ${ }^{7}$ India has a population of 1.3 billion, and hence, exerted drastic measures to prevent the spread of COVID-19, which included lockdown since $25^{\text {th }}$ March 2020. According to the Ministry of Health and Family Welfare (MoHFW), more than 5.48 million infected cases and 87882 deaths are attributed to COVID-19, as of $21^{\text {st }}$ September 2020 [7]. As of $11^{\text {th }}$ March 2020, the COVID-19 outbreak was declared a pandemic by the WHO Global and India. This required rapid capacity building to combat the pandemic.

\section{ROLE OF HEALTHCARE PROFESSIONALS}

In addition to treating the patients, numerous tasks are required to be carried out by health professionals. Breaking the transmission cycle requires containment measures, and managing clinical cases necessitates extensive human resources [8]. The management of this emergency scenario requiresInformal language maximum manpower that can be assembled, trained, and utilised skillfully. Therefore, tapping the potential of healthcare workers is crucial in this situation.

\section{WHO IS A PUBLLIC HEALTH DENTIST?}

One of the underutilised healthcare workers is a Public Health Dentist. Dental public health has been defined as 'the science and art of preventing oral diseases, promoting oral health and improving the quality of life through the organised efforts of society' [9]. Thus, a Public Health Dentist works closely with the community to address health-related issues. A Public Health Dentist has a set of core competencies and skills, as stated further. They are strong and competent leaders with management and communication skills [10]. They are also excellent team workers and are versatile to work with other health professionals, politicians, community leaders, and researchers. Planning and evaluation are the core strengths with respect to community programs. These dentists are trained in research methodology and biostatistics and have an in-depth knowledge of the basic principles of epidemiology. Also, they are updated in the field of dental health, preventive dentistry, and oral hygiene practices.

\section{ROLE OF HEALTH PUBLIC DENTIST IN COVID-19 PANDEMIC}

The potential competencies of the Public Health Dentist can be utilised in the following manner:

\subsection{Pre-screening of COVID-19}

People experienced a flood of information due to symptoms, community events, and school closures, and hence, the availability of mass media is increasing. The easiest method to obtain the right information is to call public health and government organisations. However, due to the large number of people calling for basic information, it is difficult for the person attending the calls to identify who needs assistance to get through to the right support resources over the phone. Therefore, public health dentists can help pre-screening to perform an initial triage for COVID-19 symptoms and ensure that individuals exhibiting symptoms of the disease have access to the correct support resources $[11,12]$.

\subsection{Specimen Collection}

The various specimens collected for COVID-19 diagnosis include sputum sample, nasopharyngeal and oropharyngeal swab, tracheal aspirate, bronchoalveolar lavage, nasopharyngeal aspirate or nasal wash, tissue from biopsy or autopsy (from the lung), and serum [13]. The public health dentist can collect the nasopharyngeal and oropharyngeal swab and sputum samples after adequate and specific training.

\subsection{Recording the Case History and Identification of Vulnerable Age Groups}

Please refer to the comment above.

At hospitals, a public health dentist can record detailed case history of patients reporting flu symptoms, including possible exposure source, travel, and COVID-19 contact history. A thorough analysis of demographic and socioeconomic factors from the patients could help identifying vulnerable age groups, i.e., those at high risk of the disease [11, $14,15]$.

\subsection{Assistance in Clinical Casework}

A public health dentist can assist in clinical casework by recording vital signs, testing for COVID-19, performing triage, treating emergencies (including local anaesthesia), suturing wounds, administering oxygen and drugs in injectable form, vaccinating and writing prescriptions. A brief training before starting the fieldwork would enhance their skills and boost up confidence [16].

\subsection{Community Engagement}

It is the activity through which non-profit organisations and individuals interact to build a long-term relationship that envisions the benefits for the community. The action of affected individuals, families, and communities is key to controlling public health threats/problems, and thus, it is primarily focused on empowering communities for improvement [11, 17].

The activities include providing information about the government's policy directions to the community, consulting with the community while developing a government policy, building awareness or understanding in the community, collaborating for options by partnership development, providing recommendations, and sharing leadership. These factors empower the community for decision making, implementation and management of change with respect to mechanisms, ensuring that concerns and issues are well understood. Public health dentists can effectuate this task 
adequately because they are actively involved with this community throughout their training.Please provide a subheading. Activities regarding what?

\subsection{Communication for Response and Containment}

Prevention is better than cure. Health education is the forte of public health dentists. Therefore, educating people about how the disease spreads, what are the infection control measures, the importance of hand hygiene, respiratory hygiene, social distancing, identification of high-risk groups, addressing the myths or misconceptions about COVID-19, and multiple fears that lead to stigmatising behaviour at various levels are crucial activities that can be appropriately carried out by a Public Health Dentist [18].

\subsection{Community Surveillance}

A Public Health Dentist is well trained in surveillance and It is incorrect to gender categorise a dentist.

can identify suspicious infections and the contact. Subsequently, tracing contacts, consulting contacts, and monitoring the community is crucial. Contact tracing and patient follow-up are the main strategies to prevent the further spread of COVID-19. If patients and contacts are not isolated from others before the incubation period, it causes a deadly outbreak in the community that would require the implementation of a strict prevention strategy for virus control. This specialised job includes contact identification, contact listing, and contact follow-up.It requires excellent communication skills without installing fear and stigma. The patients are informed about their contact status, the related meaning, the subsequent mandatory actions, and if the symptoms are developed, then the benefit and importance of receiving early care. The preventive aspect of the disease should also be instilled among the contacts. A public health dentist can actively carry out this task [18 - 20].

\subsection{Supportive Public Health Services}

The creation of community support for COVID-19 is a critical step. It can be ensured by providing information about the services available for home care and home quarantine for the suspected case along with the family members. The support can be extended by making available a checklist for the actions to be taken at home and public places for the prevention of COVID-19 spread. The guidelines on self/home quarantine enable a person to exert proper precautions to prevent community spread without fear or anxiety [18].

\subsection{Managing Stigma and Discrimination}

Fear and false information about the disease causes the patients and their family members to suffer stigma and discrimination from the community. Therefore, post-discharge counselling and management of patients are crucial for the rehabilitation of the patient. Public health dentists are equipped to deal with such situations as they routinely communicate with the community to remove any misconceptions [18].

\subsection{Personal Safety for Frontline Workers}

A Public Health Dentist can assist in training to ensure that all frontline workers exert appropriate self-protection measures. They are provided with a checklist for home visits and contact tracing procedures $[11,18]$.

\subsection{Capacity Building}

A Public Health Dentist can assist in capacity building by providing training and demonstrations to develop skills in individuals identified as human resources [11].

\subsection{Policy Planning and Advocacy}

One of the core competencies of a Public Health Dentist is advocacy and policy planning regarding the COVID-19 pandemic and dentistry. They can advocate for all the governmental and non-governmental dental bodies to implement the best possible measures to protect both the dentist and patients from this pandemic.

\subsection{Health Facility Infection Control Management}

The basic dentistry skills include detailed knowledge and practice of sterilisation and disinfection. It is routine in dental clinics and community-based setups that conduct screening and provide treatment. The acquired administrative skills enable a public health dentist to manage the infection at the health facility.

\subsection{Administrative Work Related to COVID-19}

A Public Health Dentist can manage the administrative management of healthcare facilities, quarantine centres, and isolation wards. The administrative skills also include appropriate allocation of manpower, material management (purchase, storage, and utilisation of essential drugs and supplies), record maintenance, budget allocation, and judicious expenditure for essentials and clinical record management.

\section{CONCLUSION}

India has approximately 1600 public health dentists [21]. Most of them work as private practitioners and academics, while some work with the government or various dental institutions/agencies. Public health dentists can provide basic and emergency services, disseminate quality information, alleviate fear, stress and anxiety, participate in various community programs and activities, and operate nongovernmental organisations (NGOs). In emergencies, such as the COVID-19 epidemic, these administrative activities are carried out skillfully. Therefore, it is necessary to use this unexplored capacity to benefit the community in such situations.

\section{CONSENT FOR PUBLICATION}

Not applicable.

\section{FUNDING}

None.

\section{CONFLICT OF INTEREST}

The authors declare no conflict of interest, financial or otherwise. 


\section{ACKNOWLEDGEMENTS}

Declared none.

\section{REFERENCES}

11] World Health Organisation. Emergencies preparedness, response Available at: https://www.who.int/csr/disease/ebola/ebola-6-months/ myths/en/

[2] World Health Organisation. Events as they happen Available at: https://www.who.int/emergencies/diseases/novel-coronavirus-2019/ev ents- as-they-happen

[3] World Health Organisation. Naming the coronavirus disease (COVID-19) and the virus that causes it Available at: https:// www.who.int/emergencies/diseases/novel-coronavirus-2019/technicalguidance/naming-the-coronavirus-disease-(covid-2019)-and-the-virusthat-causes-it

[4] World Health Organisation. Q\&A on coronaviruses (COVID-19) Available at: https://www.who.int/news-room/q-a-detail/q-acoronaviruses

[5] World Health Organisation. Coronavirus disease 2019 (COVID-19)Situation Report - 46 2019. Available at: https://www.who.int/docs/default-source/coronaviruse/ situationreports/20200306-sitrep-46-covid-19.pdf?sfvrsn=96b04adf_2

[6] World Health Organisation. Coronavirus disease (COVID-19) Pandemic Available at: https://www.who.int/emergencies/diseases/ novel-coronavirus-2019

[7] Ministry Of Health and Family Welfare. Government of India Available at: https://www.mohfw.gov.in/

[8] Ministry of Health \& Family Welfare, Directorate General of Health Services(EMR Division). Advisory for Human Resource Management of COVID-19 Available at: https://www.mohfw.gov.in/pdf/Advisory forHRmanagement.pdf

[9] Holt RD. Advances in dental public health. Prim Dent Care 2001; 8(3): 99-102.

[http://dx.doi.org/10.1308/135576101322561903] [PMID: 11490706]
[10] Springer Publishing Company. Career of the week in public health: public health dentist Available at: https://www.springerpub.com/w/ public-health/career-of-the-week-in-public-health-public-healthdentist/

[11] Dental Council of India. Advisory to the dental Professionals for COVID-19 2020. Available at: http://dciindia.gov.in/Admin/ NewsArchives/Advisory\%20for\%20Dentists\%20dated\%2013.05.2020 .pdf

[12] World Health Organisation. Available at: https://apps.who.int/iris/ bitstream/handle/10665/331915/COVID-19-algorithm-referral-triageeng.pdf? sequence $=1 \&$ is Allowed $=y$

[13] Ministry of Health and Family Welfare. Government of India 2019. Available at: https://www.mohfw.gov.in/pdf/5Sample\%20collection packaging $\% 20 \% 202019-$-nCoV.pdf

[14] World Health Organisation. Environmental health in emergencies Available at: https://www.who.int/environmental_health emergencies/vulnerable groups/en/

[15] World Health Organisation. Available at: https://www.who.int/ westernpacific/news/multimedia/infographics/covid-19

[16] California Dental Association. Dentists can register to help with state' COVID-19 pandemic response Available at: https://www.cda.org/ Home/News-and-Events/Newsroom/ Article-Details/dentists-canregister-to-help-with-states-covid-19-pandemic-response

[17] World Health Organisation. Community Engagement Module B5 Available

https://www.who.int/risk-communication/training/Module- B5.pdf

[18] Ministry of Health and Family Welfare. Government of India Available

https://www.mohfw.gov.in/pdf/FacilitatorGuideCOVID19 $27 \% 20$ March.pdf

[19] World Health Organisation. Contact tracing Available at: https://www.cdc.gov/coronavirus/2019-ncov/downloads/ php/principles-contact-tracing-booklet.pdf

[20] World Health Organisation. Contact tracing Available at: https://www.who.int/ news-room/q-a-detail/contact-tracing

[21] Indian Association of Public Health Dentistry. Available at: https://www.iaphd.org

(C) 2021 Nimbulkar et al.

This is an open access article distributed under the terms of the Creative Commons Attribution 4.0 International Public License (CC-BY 4.0), a copy of which is available at: https://creativecommons.org/licenses/by/4.0/legalcode. This license permits unrestricted use, distribution, and reproduction in any medium, provided the original author and source are credited. 